\title{
Theatro São Pedro: desenvolvimento cultural de um bem simbólico de Porto Alegre
}

\author{
Renata Bastos Dellamea Ferraz ${ }^{1}$ \\ Judite Sanson de Bem²
}

\begin{abstract}
Resumo: 0 equilíbrio financeiro do Theatro São Pedro, após sua reinauguração nos anos 1980, sempre foi um fator importante para seus gestores equacionarem, principalmente, quando suas despesas crescentes ultrapassavam suas receitas. Nesse sentido, o objetivo geral do artigo é analisar a gestão do Theatro São Pedro ${ }^{3}$ visando mostrar de que forma a Fundação Teatro São Pedro ${ }^{4}$ e a Associação dos Amigos do Theatro São Pedro ${ }^{5}$ conseguiram administrar o local a fim de garantir a continuidade de suas atividades. Os resultados apontaram para um modelo de gestão híbrido, público e privado, que possibilita manter e expandir sua infra-estrutura, garantindo uma diversidade cultural intensa nas áreas de seu complexo.
\end{abstract}

Palavras-chave: Desenvolvimento. Gestão. Theatro São Pedro.

Abstract: The financial balance of Theatro São Pedro, after its re-inauguration in the 1980s, was always an important factor for its managers to consider, mainly, when their growing expenses surpassed their revenues. In this sense, the general objective of the article is to analyze the management of Theatro São Pedro, aiming to show how the. And the Association of Friends of Theatro São Pedro were able to manage the place in order to guarantee the continuity of its activities. The results pointed to a hybrid management model, public and private, that allows to maintain and expand its infrastructure, guaranteeing an intense cultural diversity in the areas of its complex.

Keywords: Development. Management. Theatro São Pedro.

\section{Introdução}

Ao final do século XIX surgia, em Porto Alegre, o Theatro São Pedro, palco de muitos espetáculos, o qual marcou uma nova fase na vida cultural da cidade proporcionando, às

\footnotetext{
${ }^{1}$ Doutoranda do PPG em Memória e Bens Culturais da Universidade Lasalle. O presente trabalho foi realizado com apoio da Coordenação de Aperfeiçoamento de Pessoal de Nível Superior - Brasil (CAPES). Ilamea@terra.com.br

${ }^{2} \mathrm{Dr}^{\mathrm{a}}$. em História íbero Americana pela PUC (RS). Docente do PPG da Universidade Lasalle/Canoas. judite.bem@unilasalle.edu.br

${ }^{3} \mathrm{O}$ presente artigo se refere a uma parte da tese que está sendo desenvolvida pela doutoranda.

${ }^{4}$ Escreve-se Fundação Estadual Teatro São Pedro, ou seja, a palavra "Teatro" conforme a lei de criação da Fundação não inclui a letra " $h$ ", seguindo a regra ortográfica.

${ }^{5}$ Pela regra ortográfica a palavra "teatro", substantivo comum masculino, se escreve sem a letra " $\mathrm{h}$ ". Por uma decisão de imagem, a Associação Amigos do Theatro São Pedro adotou a escrita com a letra " $h$ ". Nesse sentido, quando o texto se referir ao teatro como substantivo se escreverá sem a letra " $\mathrm{h}$ ", e quando se referir o nome próprio se escreverá com a letra " $h$ ".
} 
diferentes classes sociais, apresentações nacionais e internacionais que fascinavam o público presente. Mesmo com seu fechamento, nos anos de 1970, a mobilização para reabri-lo envolveu a sociedade civil, empresários e governos, tamanha era a importância que esse espaço público havia adquirido. O teatro se tornara uma herança, um legado, um patrimônio cultural, um local de construções de memórias, identidades, imaginação e significados diversos onde sua manutenção e conservação começaram a exigir cuidados ampliados para sua continuidade. O Theatro São Pedro, considerado como um bem simbólico, fez com que seus gestores construíssem um projeto identitário que garantisse esse reconhecimento e, ao mesmo tempo, que priorizasse a gestão financeira para torná-lo viável, visando suplementar os recursos insuficientes para atender às demandas.

Nesse sentido, estudar mais especificadamente esse fenômeno representa reconstruir a memória e a história de um teatro que há mais de cem anos vive, ou melhor, "sobrevive" entre apresentações que tanto fascinam o público, e um limite de recursos que, muitas vezes, compromete sua programação cultural. Ao longo desse tempo, o local não apenas promoveu entretenimento para a população, mas também incentivou o desenvolvimento social e educacional da cidade com a abertura de instituições de ensino de artes e oportunidades de trabalho para artistas locais.

Com a existência do Theatro, Porto Alegre ganhou projeção diante outros Estados, detentora de uma referência cultural, onde artistas de fora se programam para subir sob seus palcos. Tido como uma herança cultural, ou ainda, como patrimônio cultural, o São Pedro carrega significados históricos pela presença de figuras políticas e da elite gaucha que frequentavam seu espaço bem como pelos impactos que sofreu diante das guerras e planos econômicos que comprometeram a apresentação de seus espetáculos. Mais ainda, o teatro carrega uma identidade, possui sentido, e as representações construídas ao seu redor ultrapassam o valor histórico do prédio. As experiências que os indivíduos tiveram antes de seu fechamento e após seu retorno foram relações construídas com significados que o transformaram num símbolo cultural.

Diante disso, o presente artigo busca analisar a gestão do Theatro São Pedro e para isso se encontra subdivido em quatro seções. A primeira apresenta um referencial teórico sobre memória e patrimônio; a segunda aponta a trajetória histórica do teatro após sua 
reinauguração nos anos 1980; a terceira mostra o modelo de gestão compartilhado entre órgão público e privado e a quarta analisa os dados quantitativos de sua gestão.

\section{Theatro São Pedro: memória e patrimômio}

Localizado no centro de Porto Alegre, em frente à Praça da Matriz, entre a Assembleia Legislativa e o Palácio Piratini, o Theatro São Pedro resiste ao tempo. Desde sua inauguração, no século XIX, o teatro representava não apenas um palco, mas também "para muitas pessoas, um lugar para vivenciar e imaginar o passado" (D'AMBROSI; MEIRELLES, 2014, p. 73). Imaginação que serve como dispositivo simbólico para a construção da identidade, vinculada à condição humana onde "[...] todas as épocas têm as suas modalidades específicas de imaginar, reproduzir e renovar o imaginário, assim como possuem modalidades específicas de acreditar, sentir e pensar." (BACZKO, 1985, p. 308). O teatro é, dessa forma, um espaço de memória e imaginação, lugar de rememorização ativa, em constante transformação e de significados diversos.

No livro "Theatro São Pedro: 150 anos de história", publicado em 2008, em comemoração ao seu aniversário, é possível encontrar explicações do porquê ser um local que remete à imaginação. Que lembranças permanecem vivas na memória e quais experiências, histórias, símbolos e ideias se vinculam com o Theatro São Pedro são questões que norteiam a obra. Os depoimentos de artistas, músicos, cantores e gestores que fazem parte da publicação remetem a memórias individuais e coletivas construídas a partir de pontos de referências, de quadros sociais e de experiências. Memórias que são contínuas e flexíveis. (HALBWACHS, 1990). Conforme os depoimentos, o Theatro contempla significados diversos como um local que faz parte da vida e carreira dos artistas, além de ser considerado um teatro de filme, luxo, sonho, deslumbrante e de beleza arquitetônica onde prevalece em seu ambiente, democracia e história. Em outros depoimentos, tem-se que o teatro representa um local de encontro, um espaço extraordinário para troca experiências e uma instituição que desenvolveu um modelo de gestão eficiente através de Eva Sopheri', considerada como a "alma" do local. 
Ou seja, representações do Theatro associadas em categorias e nomes que refletem relações e não apenas um processo de classificação. (MOSCOVICl, 2015). Memórias que não se restringiram unicamente a esquemas de representação característica da memória histórica, mas sim memórias vivas de caráter construtivista da recordação e da formação da identidade. (HALBWACHS, 2006). Símbolos construídos por desejos, aspirações e motivações passíveis de classificação, tradução de valores, ações e comportamentos. (BACZKO,1985).

O Theatro São Pedro, nesse sentido, evoca memórias que sobrevivem ao tempo, podendo em seu espaço ter "[...] a sensação de estar realmente vivendo na época do império [...] E, lá, fugazes partículas do presente reacendem a vivência do passado no tempo presente." (D’AMBROSI; MEIRELLES, 2014, p. 73). Mais que isso, o São Pedro é um produto de atribuição cultural, composto de dimensão simbólica, identidade, memória, vinculando laços sociais essenciais para a vida coletiva. (SILVA, 2010). Ou seja, o local reconstrói memórias que ultrapassam o tempo de vida do indivíduo, característica da memória cultural, onde através da cultura, homens e mulheres criam um quadro temporal que transcende a duração da vida individual relativa ao passado, presente e futuro. Memória cultural que permite aos indivíduos orientarem-se pelos espaços da recordação, vinculada à temporalidades,:onde "recordando, interagindo, lendo, comentando, criticando e discutindo os seres humanos participam de horizontes alargados de significado e produção." (ASSMANN, 2011, p.73)

Nesse aspecto, o reconhecimento do Theatro São Pedro como valor cultural se deu através de seu tombamento, transformando-o em um patrimônio oficial. Tombamento cedido pelo poder público à bens vinculados a fatos memoráveis da história. Considerado como patrimônio cultural, o Theatro é portador de identidade e memória, evoca um tempo, um espaço, uma natureza afetiva, uma memória viva capaz de produzir uma nova duração das coisas. (CHOAY, 2014). Com a junção dos termos, patrimônio e cultura, é "[...] possível chegar a um novo resultado [...] como uma herança coletiva, fruto da materialização da história e de elementos de memória de um grupo social." (SILVA; MELLO, 2014, p. 759). O Theatro São Pedro, assim, é um bem herdado pela comunidade, é um objeto que possui um "nexo de pertencimento". Nesse aspecto, quando se atribui valor cultural a um bem considerado patrimônio em é "[...] possível problematizar acerca da relação entre sujeito e 
patrimônio, suas aproximações e afastamentos, assim como as formas de apropriação deste conceito pelo grupo social [...]" (SILVA; MELLO, 2014, p. 759)

Patrimônio possui sentido, é uma representação construída no imaginário social. Meira (2008, p.106) destaca que " [...] é por meio dos imaginários sociais que uma coletividade elabora uma representação de si, exprime e impõe crenças comuns, organiza a distribuição dos papeis e as posições sociais, enfim, designa suas identidades." Ou seja, "[...] o conjunto de bens que formam o patrimônio cultural é referencial para a geração e manutenção das identidades, trazendo para o presente alguns elementos do passado que são, em qualquer forma, portadores de sentidos." (SILVA; MELLO, 2014, p. 763). Estando à sociedade em permanente transformação, o patrimônio remete para uma instituição e para uma mentalidade e somente com a investigação do sentido dado ao monumento histórico é que as ações de preservação devem ser implementadas. (CHOAY, 2014)

O teatro visto como patrimônio, portanto, significa estar em constante mudança, envolvendo compreender a sensibilidade de um momento, influência política de um determinado grupo social e tensões sociais de um período. Mais ainda, como patrimônio o teatro é um produto no mercado de bens simbólicos fundamental para o desenvolvimento, envolvendo fatores econômicos, políticos, educacionais e afetivos permitindo estabelecer diretrizes para uma gestão total. (BOLÁN, 2010) Ou seja, o desenvolvimento passa a ser composto sob duas dimensões: uma econômica onde "a sociedade empresarial local utiliza sua capacidade para organizar, da forma mais producente possível, os fatores produtivos da região" e outra sócio-cultural onde "[...] os valores e as instituições locais servem de base para o desenvolvimento da região." (BARQUEIRO apud FILHO, 2001, p. 88)

Se nos anos 80, as teorias focavam na endogeneidade, hoje tem-se presente abordagens que trazem elementos como sustentabilidade, território, participação cidadã e valores culturais. Ou seja, fatores antes não analisados pelas teorias clássicas enaltecem a importância do espaço local como "o lócus privilegiado em que ocorre de fato esse desenvolvimento." (ANDION, 2003, p. 1044). Cultura e patrimônio como elos fundamentais do desenvolvimento. Nessa perspectiva, os termos território e territorialidade se mostram importantes para o processo de desenvolvimento num sentido mais plural. Território entendido como "um campo de forças, uma teia ou rede de relações sociais", enquanto que 
territorialidade tida como "[...] relações entre um indivíduo ou grupo social e seu meio de referência, manifestando-se nas várias escalas geográficas [...] e expressando um sentimento de pertencimento e um modo de agir..." (ALBAGLI, 2004, p. 28) Como dimensões de territorialidade pode-se ter a física, a política-organizacional, a simbólica e a econômica, sendo que a dimensão simbólica engloba as relações culturais e afetivas entre um grupo e lugares particulares. Nessa dimensão, o território é produto da formação de identidades individuais e coletivas onde as representações "[...] sociais, imagens, símbolos e mitos projetam-se e materializam-se no espaço, transformando-se em símbolos geográficos, fornecendo referências e modelos comuns aos atores sociais e cristalizando-se uma identidade territorial." (ALBAGLI, 2004, p.40)

\section{Theatro São Pedro: novo ciclo cultural}

Nos seus mais de 115 anos de existência, o São Pedro foi uma casa aberta a todos, acolhendo apresentações qualificadas e heterogêneas. A mensagem que o local transmitia permitia receber "[...] com a mesma hospitalidade espetáculos e realizações de toda a espécie, desde apresentações de companhias dramáticas e líricas até convenções de partidos ou formaturas de estabelecimento de ensino." (DAMASCENO et al., 1975, p. 302) No entanto, com o passar do tempo, sua infraestrutura foi ficando desgastada necessitando de uma inevitável reforma, e em 1974 o local fechou suas atividades, aguardando o momento de sua reabertura.

Sem recursos financeiros para sua conservação "[...] o teatro já não tinha mais a centralidade social usufruída no passado [...]", pois em seu entorno o crescimento populacional, a revolução imobiliária, a ascensão de novos bairros, a verticalização dos prédios, a extensão dos limites da cidade, a disseminação dos meios de comunicação e transporte contribuíram para diminuir o público do local. (AXT, 2008, p.73). No entanto, o Theatro São Pedro, persistia na paisagem urbana. Permanecia com vestígios de uma espécie de herança, testemunhos e representações carregadas de valores humanos e aspirações

pessoais, como toda a cidade que tem sua história e suas formas que " [...] se dinamizam ao longo do processo." (MATTAR, 2010). 
Mesmo com a abertura de outros espaços culturais no século XX, o Theatro São Pedro "[...] continuou sendo o mais importante para os consagrados artistas brasileiros que faziam questão de se apresentar nesse espaço cultural". (D'AMBROSI; MEIRELLES, 2014, p. 71). Continuava vivo na memória e sua restauração era uma questão de tempo e envolvimento da sociedade. Conforme aponta Pesavento (2004, p.1597) recuperar a cidade do passado implicava em "[...] registrar lembranças, relatar fatos, celebrar personagens, reconstruir, reabilitar ou restaurar prédios, preservar materialmente espaços significativos do contexto urbano", mas mais, ainda, implicava em ir além dos domínios do simbólico e do sensível, implicava em "[...] sobretudo, fixar imagens e discursos que possam conferir uma certa identidade urbana, um conjunto de sentidos e de formas de reconhecimento que a individualizem na história."

Dentro dessa ideia, a recuperação do São Pedro envolvia identidade, história e sentido que permaneciam no espaço da cidade, nas lembranças e memórias individuais e coletivas. Em 1974, Eva Sopher ${ }^{6}$ assumiu, através de Secretaria da Educação do Estado, a responsabilidade de mobilizar recursos financeiros para sua reconstrução e instituir a cultura como prioridade na agenda política dos administradores públicos "[...] pois nem todos estavam efetivamente convencidos de que valia a pena investir recursos públicos naquele velho casarão em ruínas [...] numa época em que não existiam as leis de incentivo à cultura." (AXT, 2008, p.73).

A partir de então, o movimento de sensibilização perante a opinião pública era fundamental para pressionar os administradores públicos a retomar a prioridade na área da cultura, onde em 1982, o Theatro São Pedro transformou-se numa Fundação Estadual pertencendo à estrutura organizacional da Secretaria da Cultura do Estado do Rio Grande do Sul, o que permitiu receber recursos do orçamento do Estado e governo federal, agilizando o processo de reconstrução. A Fundação tinha como objetivo não apenas a captação desses recursos, mas também a finalidade de administrar o teatro; zelar pela manutenção de um elevado nível artístico da programação; colaborar com instituições públicas ou privadas no

\footnotetext{
${ }^{6}$ De origem alemã, veio para o Brasil durante a II Guerra Mundial. Na década de 1970 assumiu a direção do teatro para trabalhar no processo de restauração. Desde 1985 é a Presidente da Fundação Theatro São Pedro e membro permanente da Associação Amigos do Theatro São Pedro (HOHLFELDT, 1991).
} 
desenvolvimento e incentivo à música e às artes cênicas; e promover atividades e exibições de caráter artístico e cultural. (RIO GRANDE DO SUL, 1982)

Dois arquitetos foram convidados para fazer parte do processo, Carlos Antônio Mancuso e Antônio Carlos Castro, onde a determinação era que a arquitetura do teatro deveria ser mantida, respeitando sua identidade histórica, unindo o original e o moderno, a tecnologia e a tradição "[...] para dotar a cidade de uma moderna e confortável casa de espetáculos". (AXT, 2008, p. 83). Ou seja, distanciando-se do pensamento de que o destino das construções do passado é serem consumidas pelo tempo "[...] arquitetos e historiadores preocupam-se em intervir no processo, preservando memória, sentido, história." (PESAVENTO, 2004, p.1603) Para Eva Sopher, a filosofia da obra era devolver "[...] sua atmosfera, acolhedora e bela ao mesmo tempo, inserindo nela os recursos da atual tecnologia. Era devolver à Capital aquele monumento que dela fazia uma Capital, era devolver ao porto-alegrense sua memória." (THEATRO SÃO PEDRO, 1984, p. 13).

Ou seja, o local deveria preservar seus símbolos, valores e crenças construídas ao longo de sua existência. A passagem do tempo havia castigado sua estrutura física, restando pouca coisa antiga e a restauração faria conservar e revelar o valor estético e históricocultural do monumento, e seu significado simbólico. De posse disso, foram resgatados o volume e acústica, gradis e portas, e as poltronas, a partir de um fragmento de veludo francês; e substituídas as telhas portuguesas, as vigas de madeira pelas de aço, escadas laterais cederam lugar às instalações sanitárias, pintura do forro, iluminação sobre os palcos, laterais e camarotes, aparelhagem de som, cortinas automáticas e climatização. O palco foi ampliado, o lustre foi recriado ganhando um mecanismo de subir e descer, e escavações no subsolo puderam aumentar a área total do teatro. Finalizada a obra, o teatro foi efetivamente reinaugurado, em 1984, retornando ao espaço urbano.

Desde seu fechamento até sua abertura, nove anos se passaram para que o local fosse entregue novamente à cidade onde a gestora Eva Sopher marcou seu trabalho por sua “obstinação germânica, sensibilidade italiana e trabalho açoriano." (AXT, 1984, p. 55). Figura humana que se confunde com o teatro, Eva Sopher atesta em suas memórias, a condição precária que o São Pedro estava, mas a tarefa de adotar aquele "templo secular" como parte 
de sua vida foi seu maior desafio de trabalho, acreditando que se assim não fosse a demolição do local se tornaria realidade (THEATRO, 2008).

\section{Theatro São Pedro: modelo híbrido de gestão}

Não sendo suficientes os recursos provenientes da Fundação para a manutenção do local, em 1985, Eva Sopher criou, em paralelo, a Associação Amigos do Theatro São Pedro, entidade de promoção cultural e artística com finalidade de apoiar as atividades afins da Fundação, através da captação de recursos financeiros junto às pessoas, físicas ou jurídicas, públicas ou privadas, associadas ou não, para a execução de projetos, programas ou plano de ações (ASSOCIAÇÃO, 2010).

O local hoje ocupa uma área de $25 \mathrm{mil} \mathrm{m}^{2}$ e sua infraestrutura em nada lembra o período de sua reconstrução, nos anos de 1970 e 1980, em que o São Pedro era apenas um único palco. A necessidade de estender a área física seguia as novas tendências culturais que as casas de espetáculos precisavam ter para atender a demanda crescente fazendo com que o governo estadual cedesse um espaço correspondente a dez terrenos ao lado do teatro. (D’AMBROSI; MEIRELLES, 2014, p. 72) Hoje, o São Pedro é formado por um complexo cultural que inclui o teatro principal e um anexo denominado de Multipalco São Pedro. Sua Missão é "encantar, divertir e emocionar as pessoas, através da apresentação de teatro, música, dança e ações culturais de qualidade, contribuindo para a democratização da cultura"; sua Visão é "constituir-se, junto ao Multipalco Theatro São Pedro, em um grande centro de referência das artes de palco da América Latina."; e seus Valores são "qualidade artística, respeito ao patrimônio público, e crença na energia e no talento das pessoas" (THEATRO SÃO PEDRO, 2017).

O complexo envolve os seguintes espaços: Praça Multipalco, Concha Acústica, Du'Attos Restaurante Multipalco, Área Administrativa; Sala de Atendimento aos Associados, Salas de Reunião, Sala da Música, Centro Cultural Refap, Salas Múltiplas, Sala da Dança, Teatro Italiano, Entrada Principal, Cine Teatro Oficina, Cafeteria e Bar, Sala da Imprensa, Lojas, Estacionamento e Memorial, como retrata a Figura 1 a seguir. 
Figura 1 Vista aérea Theatro São Pedro e Multipalco São Pedro

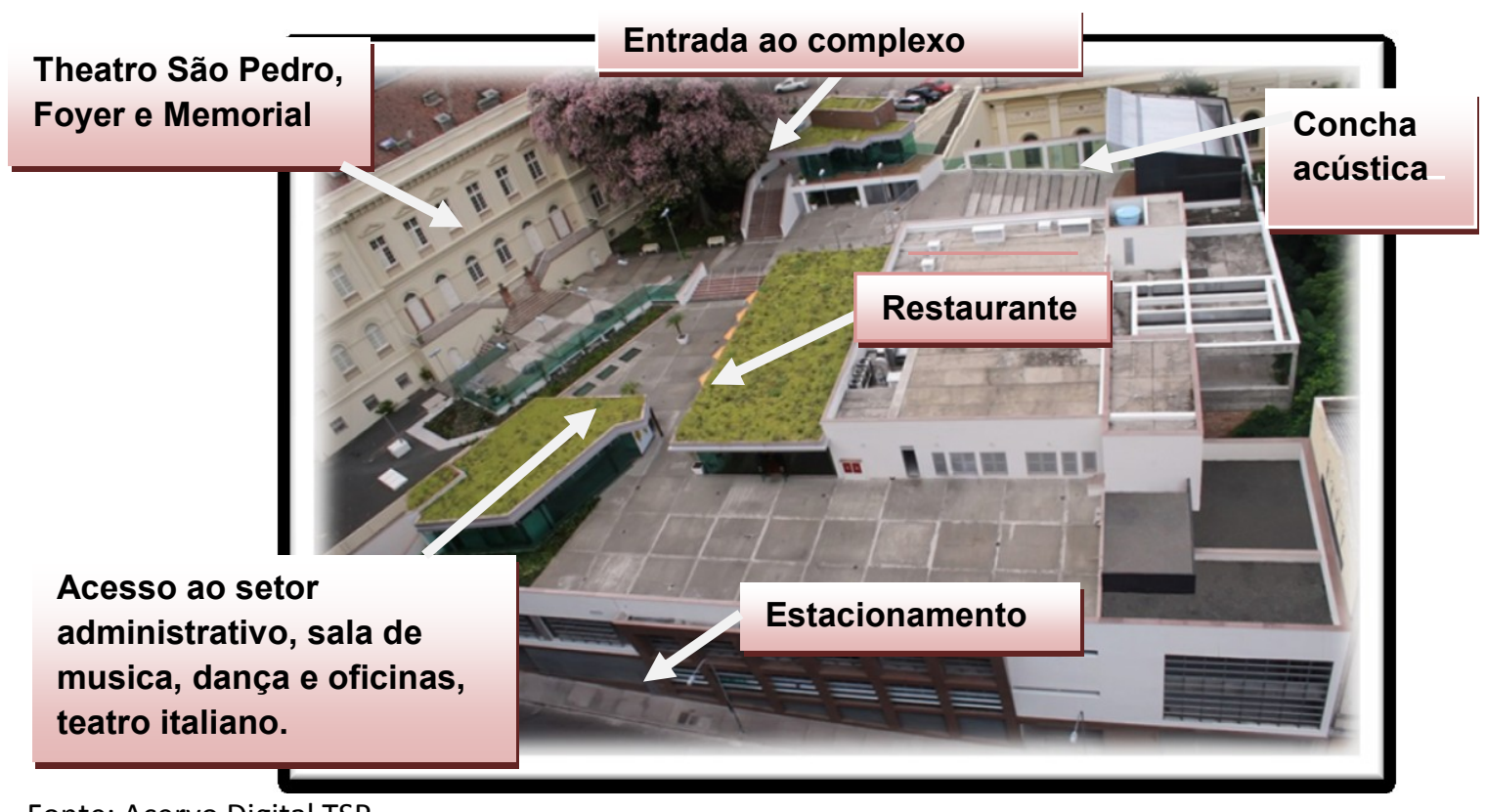

Fonte: Acervo Digital TSP.

Como se vê, a estrutura física é grande, exigindo organização e recursos para manter suas dependências em uso. Pela vista aérea (figura 19) é possível ver como se distribui seu complexo. O Theatro se posiciona ao fundo e os demais espaços como estacionamento, concha acústica, restaurante e setor administrativo na área anexa. A histórica fachada do Theatro e a praça multipalco são as entradas de acesso principais. O Estacionamento situa-se na lateral do complexo e sua fachada externa oportuniza acesso rápido à via pública.

Por ser considerado um patrimônio cultural sua gestão é de responsabilidade da administração pública através da Fundação Estadual Teatro São Pedro que tem a finalidade de administrar o teatro; zelar pela manutenção de um elevado nível artístico da programação que vier a realizar; colaborar com instituições, públicas ou privadas, no desenvolvimento e incentivo à música e às artes cênicas em nosso meio; e promover atividades e exibições de caráter artístico e cultural. (RIO GRANDE DO SUL, 1982) Quanto a sua estrutura organizacional, a Fundação possui uma Presidência, um Conselho Deliberativo e um Conselho Curador, além de três Diretorias, a Artística, a Operacional e a Administrativo-Financeira, cada uma com suas próprias competências. O Conselho Deliberativo é composto de membros da Secretaria da Educação e Cultura; da Fundação

\footnotetext{
${ }^{7}$ Entidade pública criada pela Lei $n^{\circ}$. 7.582/86, e Estatuto pelo Decreto No. 32.352/86.
} 
Orquestra Sinfônica de Porto Alegre (OSPA); da Universidade Federal do Rio Grande do Sul; Prefeitura Municipal de Porto Alegre; e de membros e suplentes de livre escolha do Governador do Estado. (RIO GRANDE DO SUL, 1982)

Por mais que tenha autonomia administrativa e financeira, a Fundação é supervisionada pela Secretaria da Cultura do Estado e Ministério Público, e fiscalizada pela Contadoria e Auditoria Geral do Estado além do Tribunal de Contas. Seu patrimônio é constituído pelos bens imóveis, móveis e direitos; doações, heranças ou legados; prédio atual e seus anexos, e materiais e equipamentos de propriedade do Estado. Sua receita compreende as rendas decorrentes da exploração dos seus bens ou prestação de serviços; contribuições, subvenções e auxílios e outros. O exercício financeiro é anual e a prestação de contas é feita semestralmente. (RIO GRANDE DO SUL, 1982)

Ao mesmo tempo, a Associação Amigos do Teatro São Pedro é gestora do espaço como entidade de promoção cultural e artística e tendo como finalidade apoiar as atividades afins da Fundação, através da captação de recursos financeiros junto à pessoas, naturais ou jurídicas, públicas ou privadas, associadas ou não, para a execução de projetos, programas ou plano de ações. A Associação não tem finalidade lucrativa, não remunera os ocupantes dos seus cargos e sua estrutura organizacional está subdividida em quatro órgãos, Assembleia Geral, Conselho Deliberativo, Conselho Fiscal e Diretoria Executiva (Diretoria Administrativa e Diretoria Financeira). Nas Assembleias Gerais, somente o associado que estiver quite com a contribuição e que já tiver um ano de contribuição pode participar, votar e ser votado. (ASSOCIAÇÃO, 2010)

O Conselho Fiscal é composto de um representante da Fundação e de Membros eleitos que deliberam acerca do funcionamento do teatro. Os membros são classificados em permanentes, associados fundadores da Associação; natos, Presidente da Associação e Presidente da Fundação; e eleitos, associados eleitos pela Assembleia Geral. Constituem renda e patrimônio da Associação, as contribuições dos associados, as doações, os patrocínios, as subvenções, bem como todos os valores e bens móveis e imóveis a que venha possuir. A prestação de contas deve ser submetida à Assembleia Geral e à Secretaria de Cultura do Estado, e em cada encerramento do seu exercício fiscal a Associação deve dar publicidade de sua gestão orçamentária. (ASSOCIAÇÃO, 2010) 
A Associação conta com mais de mil associados e uma equipe de trabalho composta de cerca de 50 funcionários, conforme atesta uma das gestoras que há mais de 10 anos trabalha na gestão. A Associação gerencia os recursos vindos do Estado e suas próprias rendas, ou seja, o teatro instituiu um modelo de gestão híbrido, onde iniciativa pública e privada atuam conjuntamente na tomada de decisão com o mesmo objetivo, que é desenvolver e incentivar a cultura local, mas cada uma com estruturas e processos diferentes de administrar o complexo.

\section{Theatro São Pedro: resultados de sua gestão}

A transformação do Theatro São Pedro, ao longo dos anos, fez com que sua área exigisse maiores recursos para fazer frente as suas despesas de manutenção e expansão. Para isso, tanto a Fundação como a Associação são responsáveis pela captação de recursos que possam garantir o andamento das atividades diárias do local. Analisando, especificadamente os dados disponibilizados pela Secretaria da Fazenda do Estado dos últimos 15 anos, os recursos destinados à Secretaria da Cultura em comparação com os outros órgãos da administração direta do estado, sempre representou menos que $1 \%$ do total, denotando a frágil prioridade dos governos nessa área. (SEFAZ, 2017)

Para evidenciar esse movimento, entre 2000 à 2015, a despesa empenhada por função do orçamento do Estado destinada à Secretaria da Cultura, conforme Tabela 1, sofreu uma queda expressiva de 54\% comparando 2000 e 2015. Desses valores empenhados, o governo destinou efetivamente para a pasta da cultura, em todos os anos, valores menores que os estimados, onde em 2000 representou 81,43\%; 2005, 76,96\%; 2010, 93,82\%; e em $2015,79,95 \%$.

Tabela 1 - Despesa Empenhada e Paga, em milhões de R\$, orçamento do Estado, para a Secretaria da Cultura - 2000-2015

\begin{tabular}{rrrrc}
\hline \multicolumn{1}{l|}{ Anos } & Despesa Empenhada & Despesa paga & $\%$ \\
\hline $\mathbf{2 0 0 0}$ & $87.942 .477,91$ & $71.608 .983,32$ & $81,43 \%$ \\
\hline $\mathbf{2 0 0 5}$ & $22.252 .035,04$ & $17.124 .313,52$ & $76,96 \%$ \\
$\mathbf{2 0 1 0}$ & $22.776 .593,88$ & $21.369 .433,93$ & $93,82 \%$ \\
\hline $\mathbf{2 0 1 5 ^ { 1 }}$ & $40.453 .904,12$ & $32.343 .985,37$ & $79,95 \%$ \\
\hline
\end{tabular}

Fonte: SEFAZ, $2018\left({ }^{*}\right)$ Valores Dez-Acumulado

Nota': projeção. Nota²: valores inflacionados para fev 2018 
Dos valores efetivamente repassados à Secretaria da Cultura, o Teatro São Pedro, Tabela 2, representou em 2000 o menor nível chegando a ter 2,70\% do total; enquanto que em 2005 esse valor aumentou para 9,35\%. Nos anos de 2010 e 2015 o teatro recebeu 6,72\% e $8,36 \%$.

Tabela 2 - Despesa Paga, em milhões de R\$̦, orçamento do Estado, para a Secretaria da Cultura e Fundação Teatro São Pedro, 2000-2015

\begin{tabular}{ccrr}
\hline Anos & $\begin{array}{c}\text { Despesa paga à } \\
\text { Secretaria da } \\
\text { Cultura }\end{array}$ & $\begin{array}{r}\text { Despesa paga à } \\
\text { Fundação Teatro São } \\
\text { Pedro }\end{array}$ & $\%$ \\
\hline $\mathbf{2 0 0 0}$ & $71.608 .983,32$ & $1.930 .021,42$ & 2,70 \\
\hline $\mathbf{2 0 0 5}$ & $17.124 .313,52$ & $1.600 .695,30$ & 9,35 \\
$\mathbf{2 0 1 0}$ & $21.369 .433,93$ & $1.435 .914,86$ & 6,72 \\
\hline $\mathbf{2 0 1 5}$ & $32.343 .985,37$ & $2.705 .253,61$ & 8,36 \\
\hline
\end{tabular}

Fonte: SEFAZ, $2018(*)$ Valores Dez-Acumulado

Nota': projeção. Nota²: valores inflacionados para fev 2018

Além disso, os valores pagos efetivamente à Fundação não coincidiram com os empenhados, ou seja, os repasses alcançavam em média $80 \%$ do valor empenhado. (SEFAZ, 2017) Essas diferenças podem ser atribuídas pelo fato do orçamento do Estado representar uma estimativa de gastos ${ }^{8}$ quando da sua elaboração, que pode não coincidir com o valor arrecadado e/ou pago junto aos órgãos públicos ${ }^{9}$.

Nesse sentido, para manter o local em funcionamento, a Associação também atua para garantir recursos que venham cobrir as despesas totais e o fluxo das atividades culturais oferecidas no complexo, como pode-se ver na Tabela 3 e Gráfico 1. Somente em 2005, percebe-se que o estado contribuiu mais que a Associação para cobrir suas despesas totais (67,81\%). Em 2010, 2014 e 2015, a Associação participou com 58,73\%, 55,71\%\% e $55,33 \%$, respectivamente, sobre o total geral.

\footnotetext{
${ }^{8}$ O Orçamento Anual do Estado deve ir ao encontro do Plano Plurianual e da Lei de Diretrizes Básicas, conforme a Constituição de 1988, além da Lei de Responsabilidade Fiscal. Essas leis orientam os governos nos seus planejamentos orçamentários anulais. Disponível em .< http://planejamento.rs.gov.br/manualtecnico-do-orcamento-mto> Acessado em: 2 set. 2017

${ }^{9}$ Além disso, fatores econômicos e políticos interferem nesse processo, como uma queda no nível de atividade que diminua a arrecadação de impostos comprometendo as receitas dos governos.
} 
Tabela 3 - Despesas gerais totais, em mil R\$̦, da AATSP e Fundação TSP - 2005/2015

\begin{tabular}{|c|c|c|c|c|c|c|}
\hline \multirow[b]{2}{*}{ Ano } & \multicolumn{2}{|c|}{ ASSOCIAÇÃO } & \multicolumn{2}{|c|}{ FUNDAÇÃO TSP } & \multirow[b]{2}{*}{ total geral } & \multirow[b]{2}{*}{$\%$} \\
\hline & $\mathrm{RS}$ & $\%$ & RS & $\%$ & & \\
\hline 2005 & $943.627,13$ & 32,19 & $1.987 .373,06$ & 67,81 & $2.931 .000,18$ & 100,00 \\
\hline 2010 & $2.515 .713,93$ & 58,73 & $1.767 .861,88$ & 41,27 & $4.283 .575,81$ & 100,00 \\
\hline 2014 & $3.871 .617,15$ & 55,71 & $3.077 .510,32$ & 44,29 & $6.949 .127,47$ & 100,00 \\
\hline $2015^{1}$ & 4.143.601,84 & 55,33 & $3.345 .914,17$ & 44,67 & 7.489.516,01 & 100,00 \\
\hline
\end{tabular}

Fonte: Relatório de Gestão AATSP

Nota': projeção. Nota²: valores inflacionados para fev 2018

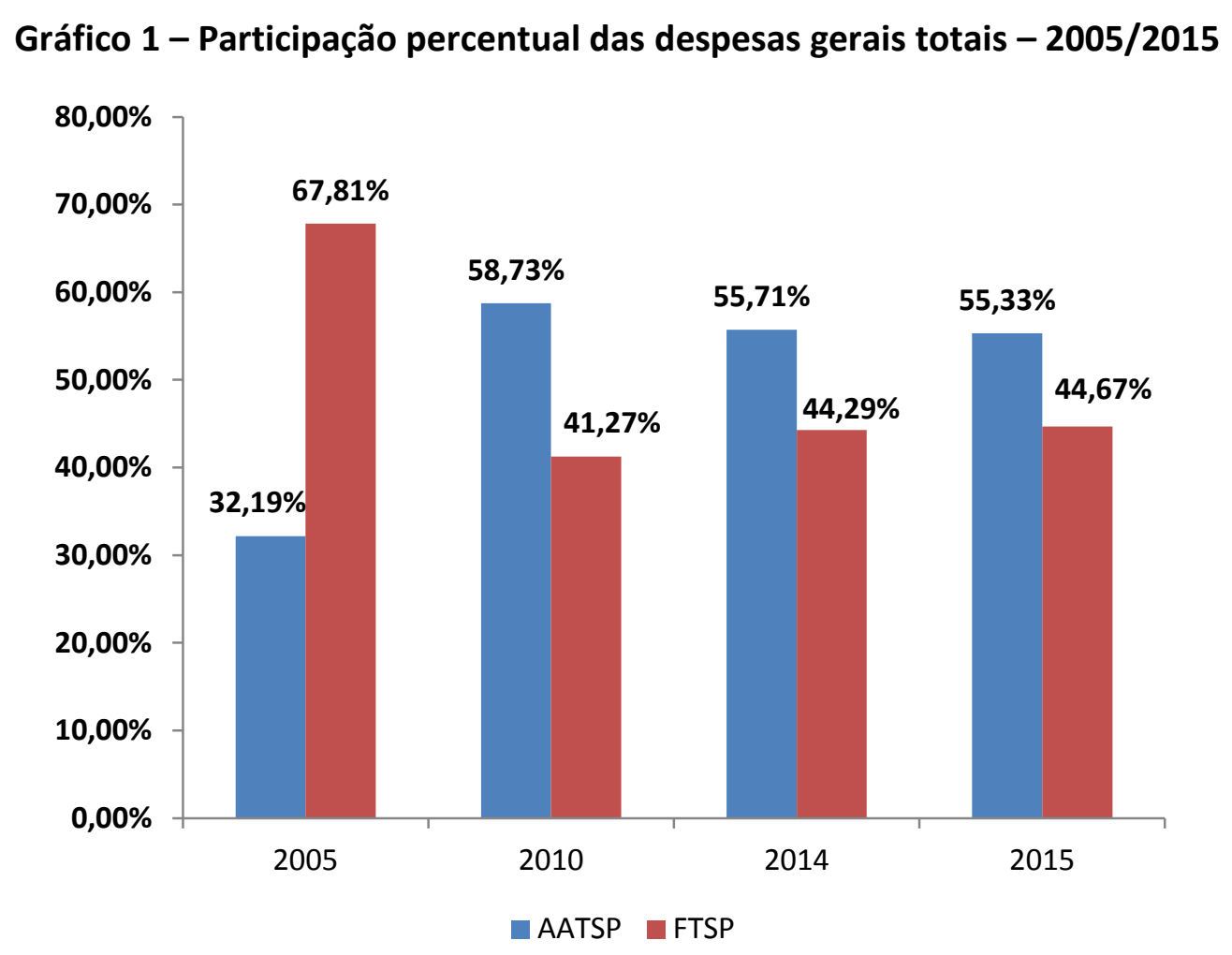

Fonte: Relatório de Gestão AATSP

Analisando as despesas com recursos humanos, a Tabela 4 e Gráfico 2 permite verificar que em 2005 e 2010 o estado despendia mais que a Associação, com 63,82\% e 51,09\%. No entanto, em 2014 e 2015, a relação se inverte, onde a Associação contribuiu com $66,66 \%$ e $73,36 \%$ sobre o total. 
Tabela 4 - Despesas, em mil R\$, com Recursos Humanos da AATSP e Fundação TSP - 2005/2015

\begin{tabular}{crrrcccc}
\hline ANO & \multicolumn{2}{c}{ ASSOCIAÇÃO } & \multicolumn{2}{c}{ FUNDAÇÃO TSP } & & \\
\cline { 2 - 5 } & $\mathbf{R}$ & $\mathbf{\%}$ & $\mathbf{R} \$$ & $\mathbf{\%}$ & total geral & $\%$ \\
$\mathbf{2 0 0 5}$ & $665.916,83$ & 36,18 & $1.174 .610,62$ & 63,82 & $1.840 .527,46$ & 100,00 \\
$\mathbf{2 0 1 0}$ & $1.927 .947,10$ & 48,91 & $2.014 .265,91$ & 51,09 & $3.942 .213,02$ & 100,00 \\
$\mathbf{2 0 1 4}$ & $3.338 .779,34$ & 66,66 & $1.669 .779,51$ & 33,34 & $5.008 .558,85$ & 100,00 \\
\hline $\mathbf{2 0 1 5}$ & $3.646 .148,03$ & 73,36 & $1.324 .155,55$ & 26,64 & $4.970 .303,58$ & 100,00 \\
\hline
\end{tabular}

Fonte: Relatório de Gestão AATSP.

Nota': projeção. Nota²: valores inflacionados para fev 2018.

Gráfico 2 - Participação percentual das despesas em Recursos Humanos - 2005/2015

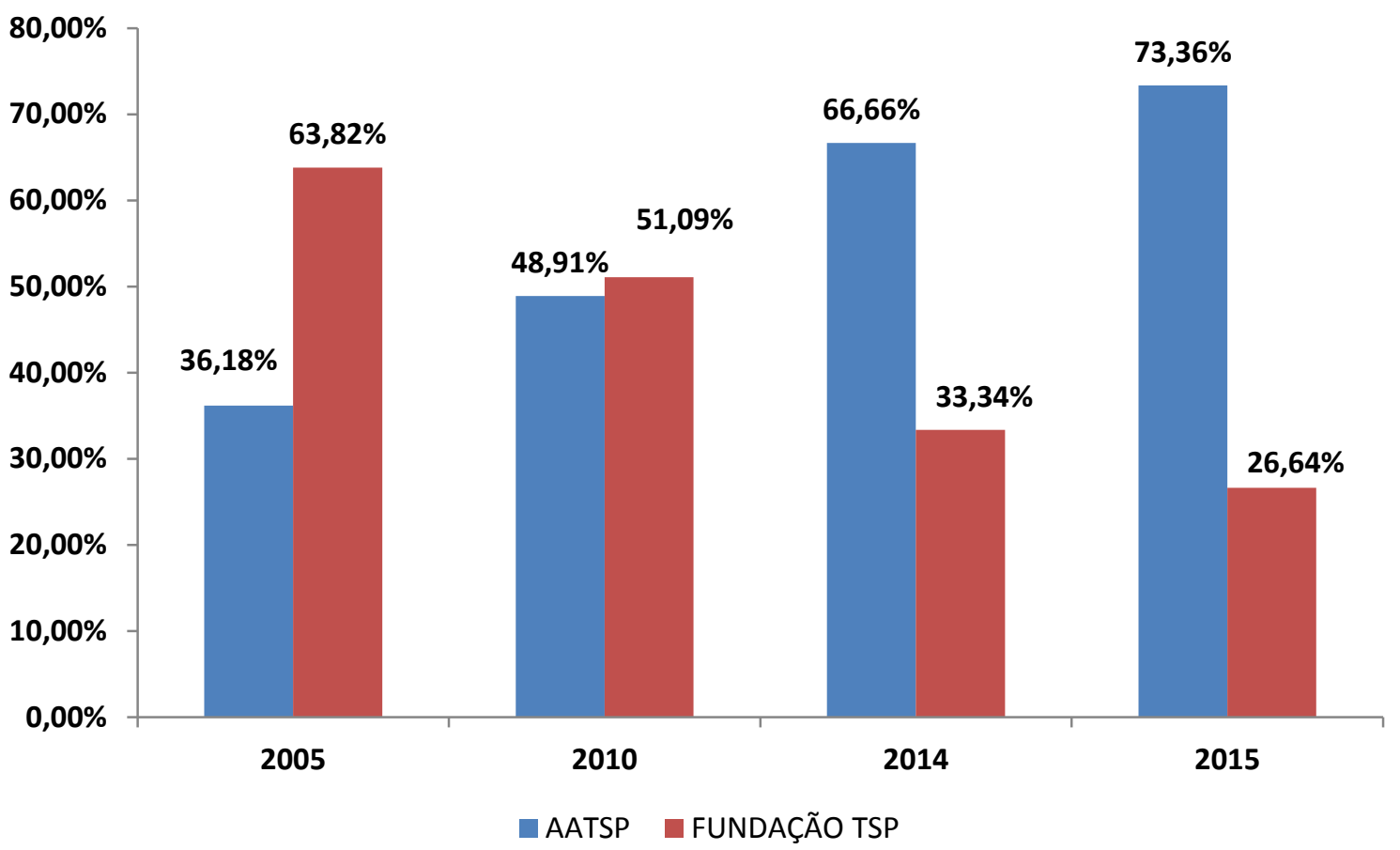

Fonte: Relatório de Gestão AATSP

Já os investimentos em infraestrutura em bens duráveis, a Tabela 5 e Gráfico 3, mostra que a Associação concentrou as despesas em 100\% nos anos de 2005, 2010 e 2015. No ano de 2014 o estado contribui com apenas 5,62\%, enquanto que a Associação participou com os recursos restantes. 
Tabela 5 - Investimento em infraestrutura - bens duráveis ${ }^{2}$ da AATSP e da Fundação TSP - 2005/2015

\begin{tabular}{|c|c|c|c|c|c|c|}
\hline \multirow[b]{2}{*}{ ANO } & \multicolumn{2}{|c|}{ ASSOCIAÇÃO } & \multicolumn{2}{|c|}{ FUNDAÇÃO TSP } & \multirow[b]{2}{*}{ total geral } & \multirow[b]{2}{*}{$\%$} \\
\hline & $\mathbf{R} \mathbf{S}$ & $\%$ & $\mathbf{R} \$$ & $\%$ & & \\
\hline 2005 & $77.900,11$ & 100,00 & $\ldots$ & $\ldots$ & $77.900,11$ & 100,00 \\
\hline 2010 & $12.605,17$ & 100,00 & $\ldots$ & $\ldots$ & $12.605,17$ & 100,00 \\
\hline 2014 & $29.489,29$ & 94,38 & $1.756,41$ & 5,62 & $31.245,70$ & 100,00 \\
\hline $2015^{1}$ & $198.708,97$ & 100,00 & $\ldots$ & $\ldots$ & $198.708,97$ & 100,00 \\
\hline
\end{tabular}

Fonte: Relatório de Gestão AATSP

Nota': projeção. Nota²: valores inflacionados para fev 2018

Nota ${ }^{3}$ : TI, móveis, equipamentos e utensílios

\section{Gráfico 3 - Participação percentual das despesas infra-estrutura - 2005/2015}

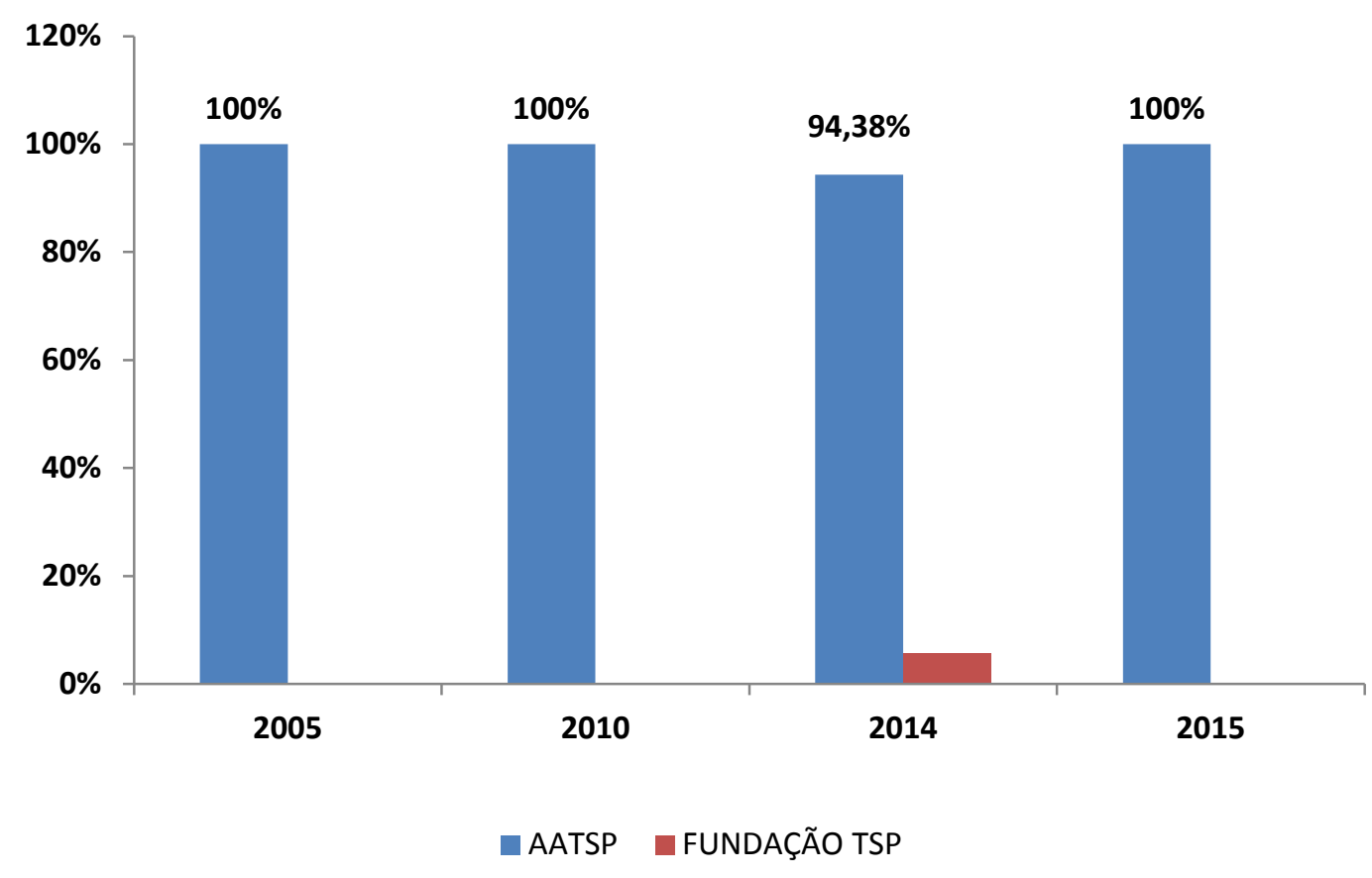

Fonte: Relatório de Gestão AATSP

No acumulado das despesas entre 2005 à 2014, pode-se observar maior participação de aportes de recursos da Associação sobre o total geral, tanto para despesas de recursos humanos quanto nos investimentos em bens duráveis com valores percentuais superiores a $55 \%$ (Tabela 6). 
Tabela 6 - Despesas acumuladas da AATSP e Fundação TSP - 2005 a 2014

\begin{tabular}{|c|c|c|c|c|c|c|}
\hline \multirow[b]{2}{*}{ Despesas } & \multicolumn{2}{|c|}{ ASSOCIAÇÃO } & \multicolumn{2}{|c|}{ FUNDAÇÃO TSP } & \multirow[b]{2}{*}{ total geral } & \multirow[b]{2}{*}{$\%$} \\
\hline & $\mathbf{R} \$$ & $\%$ & $\mathbf{R} \$$ & $\%$ & & \\
\hline Gerais totais & $19.620 .130,76$ & 55,00 & $16.055 .182,40$ & 45,00 & $35.675 .313,16$ & 100,00 \\
\hline Recursos Humanos & $14.922 .010,55$ & 57,38 & $11.082 .203,35$ & 42,62 & 26.004.213,91 & 100,00 \\
\hline $\begin{array}{l}\text { Investimentos em bens } \\
\text { duráveis }{ }^{2}\end{array}$ & $758.381,37$ & 91,94 & $66.481,56$ & 8,06 & $824.862,93$ & 100,00 \\
\hline
\end{tabular}

Fonte: Relatório de Gestão AATSP

Nota': projeção. Nota²: valores inflacionados para fev 2018

Nota $^{3}: \mathrm{TI}$, móveis, equipamentos e utensílios

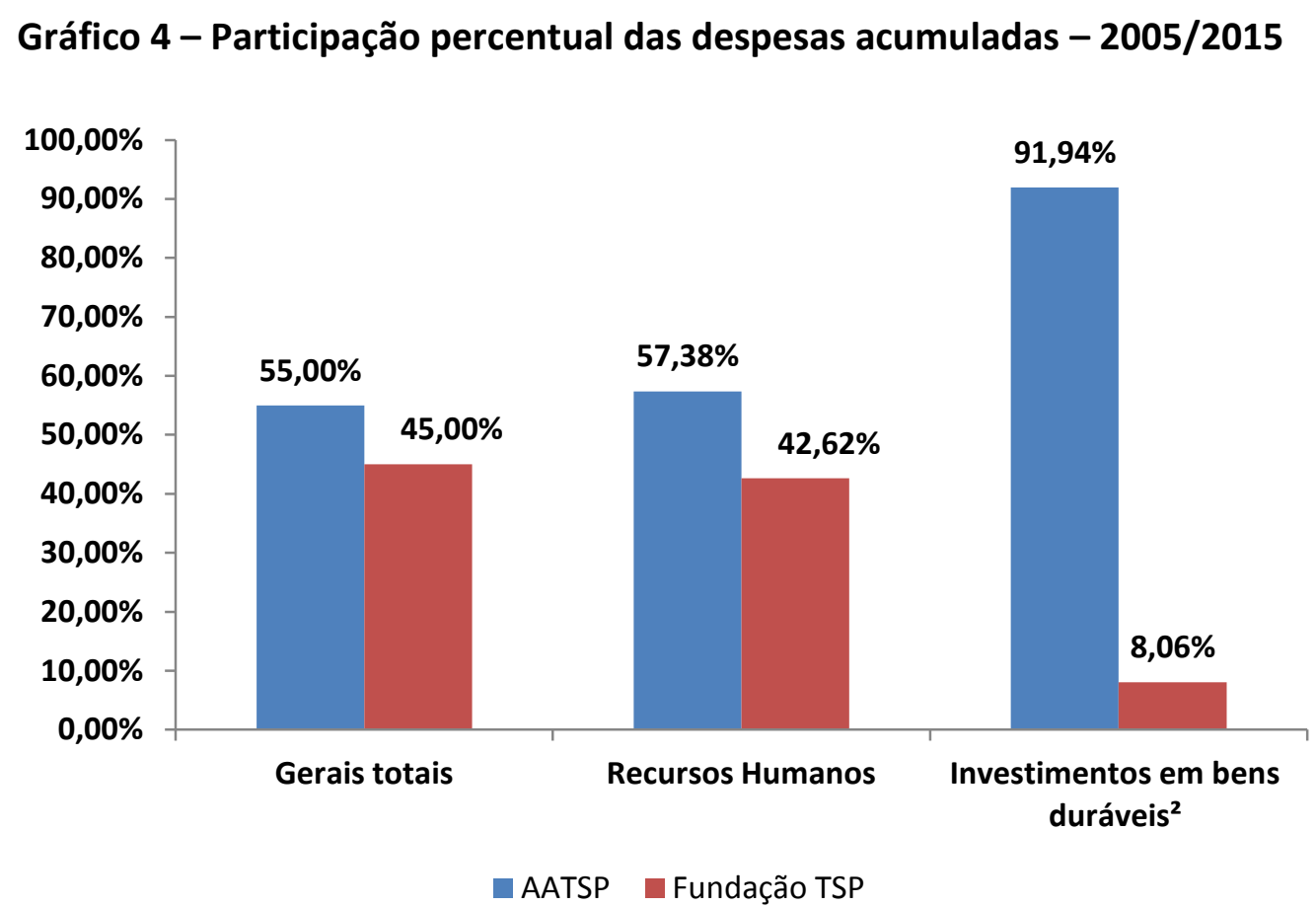

Fonte: Relatório de Gestão AATSP

Todas essas despesas objetivam a manutenção e expansão do complexo para oportunizar um conjunto diversificado de programações culturais à comunidade. A Tabela 7 atesta que, entre 2015 e 2017, o local concentrou suas atividades na música e teatro, chegando a somar mais de 80 \% sobre o total. Mas há outras programações, as quais atestam as possibilidades de diversificação que o local possibilita. 
Tabela 7 - Atividades culturais - 2015/2017

\begin{tabular}{lcccccc}
\hline \multirow{2}{*}{ Atividades } & \multicolumn{6}{c}{ Quantidade de Atividades } \\
\cline { 2 - 7 } & \multicolumn{2}{c}{$\mathbf{2 0 1 5}$} & \multicolumn{3}{c}{$\mathbf{2 0 1 6}$} & \multicolumn{2}{c}{$\mathbf{2 0 1 7}$} \\
teatal & $\%$ & total & $\%$ & total & $\%$ \\
\hline música & 30 & 30,00 & 37 & 25,69 & 48 & 22,75 \\
\hline dança & 57 & 57,00 & 76 & 52,78 & 127 & 60,19 \\
\hline exposição & 4 & 4,00 & 19 & 13,19 & 10 & 4,14 \\
\hline oficina & $\ldots$ & $\ldots$ & 3 & 2,08 & 1 & 0,47 \\
\hline seminário & 7 & 7,00 & 5 & 3,47 & 6 & 2,84 \\
palestra & 1 & 1,00 & $\ldots$ & $\ldots$ & $\ldots$ & $\ldots$ \\
\hline sarau & $\ldots$ & $\ldots$ & 1 & 0,69 & 3 & 1,42 \\
\hline conferência & $\ldots$ & $\ldots$ & $\ldots$ & $\ldots$ & 2 & 0,95 \\
\hline workshop & $\ldots$ & $\ldots$ & $\ldots$ & $\ldots$ & 1 & 0,47 \\
\hline mesa redonda & 1 & 1,00 & $\ldots$ & $\ldots$ & 2 & 0,95 \\
feira & $\ldots$ & $\ldots$ & 1 & 0,69 & 1 & 0,47 \\
total & $\ldots$ & $\ldots$ & 2 & 1,39 & 10 & 4,74 \\
\hline
\end{tabular}

Fonte: elaborado pelas autoras, conforme programação disponível no site do TSP, 2017.

Quanto à locação das apresentações em suas dependências internas e externas, podese ver que as atividades aconteceram, praticamente, em todos os espaços como mostra a Tabela 8. Entre 2015 a 2017, o palco do teatro foi o espaço dominante dos eventos artísticos do complexo. Nos anos, a sala de música cresceu de participação, onde em 2015 representava $8 \%$, e em $201721,80 \%$ sobre o total. Isso confirma o movimento da tabela anterior, que as atividades musicais cresceram com os anos. Interessante observar que a Praça Multipalco começou a ser utilizada como um espaço integrador com a comunidade, através das feiras.

Tabela 8 - Ocupação das dependências do complexo - 2015/2017

\begin{tabular}{lrrrrrr}
\hline $\begin{array}{l}\text { Quantidade de atividades } \\
\text { Local }\end{array}$ & total & \% & total & $\%$ & total & $\%$ \\
\hline Palco principal - TSP & 73 & 73,00 & 111 & 77,08 & 117 & 55,45 \\
Foyer nobre & 8 & 8,00 & $\ldots$ & $\ldots$ & 25 & 11,85 \\
\hline Concha acústica & 4 & 4,00 & 4 & 2,78 & 4 & 1,90 \\
\hline Sala de música & 8 & 8,00 & 18 & 12,50 & 46 & 21,80 \\
\hline Sala de oficina & 4 & 4,00 & 3 & 2,08 & 4 & 7,90 \\
Sala de exposições & 3 & 3,00 & 2 & 1,39 & 1 & 0,47 \\
\hline Praça Multipalco & $\ldots$ & $\ldots$ & 5 & 3,47 & 11 & 5,21 \\
\hline Memorial & $\ldots$ & $\ldots$ & 1 & 1,00 & 4 & 1,90 \\
\hline total & 100 & 100,00 & 144 & 100,00 & 211 & 100,00 \\
\hline Fon & & & & &
\end{tabular}

Fonte: elaborado pelas autoras, conforme programação disponível no site do TSP, 2017. 
Diante dessas evidências, pode-se perceber que o Estado destina valores à FTSP, da mesma forma que a Associação capta recursos para fazer frente às despesas do complexo. Nessa atuação conjunta de gestão, o local consegue gerar uma ampla diversidade de atividades culturais promovendo o desenvolvimento cultural da cidade.

\section{Considerações finais}

O objetivo geral do artigo foi analisar a memória e gestão do Theatro São Pedro após sua retomada, nos anos 80 , na cena cultural da cidade. Para isso, o referencial teórico sobre a memória e patrimônio foi apresentado dado que o teatro, mesmo com seu fechamento nos anos 70, permanecia nas lembranças do público. Sua trajetória histórica de mais de cento e cinquenta anos permanecia viva, em constante transformação, fazendo o Estado o considerar como um patrimônio cultural, ou seja, um espaço portador de referência à identidade, à ação e à memória dos grupos sociais.

Dada essa importância, sua reabertura trouxe uma nova perspectiva cultural, na medida em que a agregação de maior área física possibilitou ofertar uma diversidade de atividades para além do palco principal do teatro. Sua estrutura tornou-se um complexo formado por salas de música, dança, oficinas, praça, estacionamento, memorial entre outros; e suas atividades cresceram tanto em quantidade de apresentações como em diferentes modalidades artísticas e educacionais. Instrumento indutor de desenvolvimento cultural, é assim que o Theatro São Pedro pode ser considerado.

Para sustentar essa nova dinâmica, a forma compartilhada de gestão entre o estado e a iniciativa privada foi uma estratégia fundamental para sustentar as despesas fixas e correntes que o local exigia. Em alguns momentos, a Fundação Estadual Teatro São Pedro teve maior participação no processo, e em outros, pôde-se ver que a Associação Amigos do Theatro São Pedro teve que atuar de forma mais significativa na manutenção e expansão do espaço.

Nesse arranjo, a cidade permanece sendo referência cultural, o público se beneficia com os diferentes espetáculos e ações educacionais, o estado continua investindo na área cultural e a Associação se fortalece como entidade privada capaz de administrar com maior 
eficiência a captação de recursos que venham a consolidar o complexo como patrimônio cultural.

\section{Referências}

ALBAGLI, Sarita. Território e Territorialidade. Apud: Braga, Christiano; Morelli, Gustavo; Lages, Vinícius N. Territórios em Movimento: cultura e identidade como estratégia de inserção competitiva. Brasília, Sebrae, 2004.

ANDION, Carolina. Análise de redes e desenvolvimento local sustentável. RAP. Rio de Janeiro, 2003.

ASSMANN, Aleida. Espaços da Recordação - formas e transformações da Memória Cultural. Campinas: editora da UNICAMP, 2011.

ASSOCIAÇÃO AMIGOS DO THEATRO SÃO PEDRO. Comissão Especial de Reforma do Estatuto. Estatuto da Associação Amigos do Theatro São Pedro. Porto Alegre, 4 de outubro de 2010.

AXT, Gunter. 0 nosso Theatro: itinerário de um espetáculo sesquicentenário. In: THEATRO SÃO PEDRO: 150 ANOS. Porto Alegre: Agência RBS, 2008.

BAZCKO, Bronislaw. A imaginação social . In: Leach, Edmund et Alii.Anthropos-Homem. Lisboa, Imprensa Nacional/Casa da Moeda, 1985. Disponível em: < https://pt.scribd.com/doc/12853058/Bronislaw-Baczko-Imaginacao-Social> Acesso em: 15 jun. 2017.

BRASIL. Constituição da República Federativa do Brasil. Promulgado em 5 de outubro de 1988. Brasília,1988. Disponível em:

https://www2.senado.leg.br/bdsf/bitstream/handle/id/518231/CF88_Livro_EC91_2016.pdf Acessado em: 10 de agosto de 2017.

BOLÁN, Eduardo Nivón. Del patrimônio como producto. La interpretacion Del patrimônio como espacio de intervención cultural. 2010. In: Gestionar el patrimonio en tiempos de globalización. Universidad Autónoma Metropolitana México, pp.15-35, 2010.

CHOAY, Françoise. Alegoria do Patrimônio. Portugal: Edições 70, 2014.

DAMASCENO, Athos et. al. O Teatro São Pedro na vida cultural do Rio Grande do Sul. Porto Alegre: Departamento de Assuntos Culturais da SEC, 1975.

D'AMBROSI, Regina; MEIRELLES, Mauro. O Theatro São Pedro no espaço da cidade:

memória social e consumo da cultura. Revista Gestão e Desenvolvimento. Novo Hamburgo, Ano XI, v. 11, n.1, p. 58-76, jan, 2014.

HALBWACHS, M. A memória coletiva. São Paulo: Centauro, 1990. 
HOHLFELD, Antônio. Doce Fera: Fragmentos biográficos de Eva Sopher. Porto Alegre: Gráfica Pallotti, 1991.

FILHO, Jorge Renata de Souza. Participação e cooperação: elementos para uma nova política de desenvolvimento regional. Ensaios Fee, Porto Alegre, v. 22, n. 1, p. 86-114, 2001. Disponível em:

<http://hdrnet.org/587/1/Links\%20BO/68_Desenvolvimento_regional_endogeno_capital_so cial_coopera.pdf >_Acessado em: 20 abr. 2017.

MATTAR, Leila Nesralla. A modernidade de Porto Alegre: arquitetura e espaços urbanos plurifuncionais em área do 4\%. distrito. Porto Alegre, 2010. 354 f Tese. (Doutorado em História) Programa de Pós Graduação em História, Pontifícia Universidade Católica do Rio Grande do Sul, Porto Alegre. 2010

MEIRA, Ana Lúcia Goelzer. O patrimônio histórico e artístico do Rio Grande do Sul no século XX: atribuições de valores e critérios de intervenção. 2008.Tese (Doutorado em Planejamento Urbano e Regional) Programa de Pós-Graduação em Planejamento Urbano e Regional, Universidade Federal do Rio Grande do Sul, Porto Alegre, 2008.

MOSCOVICI, Serge. Representações Sociais: investigações em psicologia social. Rio de Janeiro: Vozes, 2015.

PESAVENTO, Sandra Jatahy. Cidade, Espaço e Tempo: reflexões sobre a memória e o patrimônio urbano. IN: Fragmentos da Cultura, Goiânia, v. 14, n. 9, p. 1595- 1604, set. 2004.

RIO GRANDE DO SUL. Assembleia Legislativa. Decreto No. 30.590 de 18 de março de 1982. Aprova o Estatuto da Fundação Teatro São Pedro. Porto Alegre, 1982.

RIO GRANDE DO SUL. Assembleia Legislativa. Lei Estadual no. 7231, de 18 de dezembro de 1978. Dispõe sobre o Patrimônio Cultural do Estado. Porto Alegre, 1978. Disponível em: < Iproweb.procempa.com.br/pmpa/prefpoa/smc/usu_doc/lei_7231_estadual.doc $>$ Acesso em: 8 ago. 2017.

SEFAZ. SECRETARIA DA FAZENDA DO ESTADO DO RIO GRANDE DO SUL. Disponível: <. https://www.sefaz.rs.gov.br/AFE/DOT-DES_1.aspx...> Acesso em: 5 ago. 2017

SILVA, Lucia. Trajetória de um Conceito: Patrimônio, entre a Memória e a História. Revista Multidisciplinar de Humanidades,Vassouras, 2010. Disponível em <

file://C:/Users/Crian\%C3\%A7a/Downloads/105-167-1-PB\%20(1).pdf> Acessado em: 30 mar. 2017

SILVA, Manuela Ilha; MELLO, Luiz Fernando da Silva. Patrimônio Cultural: conceito, sentido e lugar. In: Seminário Internacional de Memória e Patrimônio ; orgs. Marlise Buchweitz Klug. - Pelotas: Ed. da UFPel, 2014. Modo de acesso: <http://8simpufpel.wix.com/8simpufpel> 
THEATRO SÃO PEDRO. Disponível em: <https://www.teatrosaopedro.com.br/> Acesso em: 20 abr. 2017.

Álbum ilustrado comemorativo de sua reinauguração. Porto Alegre, Editora Gráfica Metrópole, 1984.

150 ANOS. Porto Alegre: Agência RBS, 2008. 